\title{
Proposed Risk Management Model to Handle Changing Requirements
}

\author{
Mohammad D. AlJohani ${ }^{\text {a }}$, Rizwan Qureshi ${ }^{\text {b,* }}$ \\ ${ }^{a, b}$ Faculty of Computing and Information Technology, King Abdul-Aziz University, Jeddah, Saudi Arabia
}

Received: 19 May 2019; Accepted: 20 June 2019; Published: 08 September 2019

\begin{abstract}
The change in requirements while construction of a software may bring into several risks like over budget and extra schedule. The changes in requirements are considered as a high risk to fail the software projects. A good project manager always incorporates risk management paradigm to manage the risks of changing requirements. This research uses available statistical techniques to estimate the cost of risk management with respect to the changing requirement. In addition, a hybrid cost estimation model is proposed using action strategy model to counteract, mitigate and manage the risks of changing requirements. The proposed model is validated using an industrial case study in Saudi Electricity Company (SEC) to conclude the results. The results are found supportive because the proposed model shows significant improvement to estimate the costs of changing requirements as compared to the existing cost estimation models.
\end{abstract}

Index Terms: Requirements Change Management, Risk Management, Case Study, Cost Estimation Models.

(C) 2019 Published by MECS Publisher. Selection and/or peer review under responsibility of the Research Association of Mode rn Education and Computer Science

\section{Introduction}

In software development processes, many developers are facing changing and challenging requirements when developing various kinds of software from the last several years. Software can serve many purposes including mobile computing applications, games development, malware protection, administrative functions and financial or payroll applications. The problem in software development is that the complexity, in fact the sheer number of technical and human resources needed and clients' changing requirements that the end product may well end up being delivered at a much later date than anticipated. Furthermore, the challenges

* Corresponding author.

E-mail address: rmuhammd@kau.edu.sa. 
outlined may cause errors and viruses to compromise the software code causing it to become ineffective, or at worst, damaged and corrupted. This is where cost calculation and risk management strategies come into play.

Function Point Analysis (FPA), COCOMO I, COCOMO II and Story point techniques can play a major role in predicting patterns of delivery, change/modification and cost of changes can hamper the successful delivery of software products. Most of these methods employ algorithms, linear regression, and differential equations to predict the software budgeting and scheduling. The majority of software projects are not free of risks [1]. It is important to deliver a given product as anticipated by the customers to make him happy and satisfied [2,3]. The software risks are more prone during the early phases of software development [4,5]. Moreover, it is critical to define, estimate, and manage risks during the planning phase [6]. The matter of a fact is that the risk of changing requirements cannot be predicted at the planning phase [4,7]. The changing requirements are an uncertain risk and it will be tackled using firefighting or fix on failure strategy. It is recommended to recalculate cost, time, effort and resources to avoid and minimize the damage [8]. However, the changing requirements may cause to fail a software project [9].

The software cost estimation techniques are used to compute cost, time, and effort to complete a project $[2,10]$. The usage of these techniques help to deliver a project within planned budget and schedule $[3,10]$. It is evident that the changes in requirements effect the planned budget, schedule and resources [4,11]. It could be necessary to obtain extra money, time and personnel in order to complete the project [12]. The existing software cost estimation techniques face challenges with respect to accuracy of budgeting and scheduling [2].

The paper is organized as follows. Section 2 outlines the related work. Section 3 describes the problem statement. Section 4 depicts the details of the proposed solution. Section 5 provides the validation of proposed solution.

\section{Related Work}

The software cost estimation models and techniques are classified in [13]. The present software cost estimation models are analogy, expert opinion, Putnam's software life-cycle model (SLIM) and constructive cost model (COCOMO). The existing software estimation models are analyzed to discuss the pros and cons of each. Analogy estimation model uses historical data to perform estimation and it is not available in most of the organizations. Delphi estimation model uses expert's opinion to derive the results. SLIM Putnam software effort estimation uses mathematical model to calculate the effort. COCOMO accuracy depends on the correct selection of cost drivers. Principal Component Analysis (PCA) uses Artificial Neural Network (ANN) to conclude the results in [14]. The objective of the research is to increase the accuracy of cost estimation. A hybrid model is proposed using Function Point (FP), COCOMO, and ANN [15]. The core objective is to increase the accuracy of cost estimations as compared to the existing COCOMO and ANN. These researches are investigated to identify the shortcomings of FP, COCOMO and PCA cost estimation models [13-15].

The research is used to propose a novel model that is based on back propagation neural network [16]. ANN is designed following the human brain. COCOMO techniques are used to implement the backpropagation neural network model. NASA 2 dataset is used to train and validate the proposed model. The results show that the proposed model is more accurate than the traditional COCOMO. Use case point (UCP) model is discussed in [17]. It is reported that the UCP model is more effective and efficient as compared to the existing models. Another ANN based extension of COCOMO is presented in [18] to solve the challenges of existing cost estimation models. The errors identification is less costly if the software development is at its early stages [12] A decision table is used to present bugs those may raise in the later stages of software development. There is no coding requirement to implement the proposed model. The proposed model uses regression analysis to estimate the cost [19]. The regression analysis is a statistical approach measured the correlation between variables. The proposal aims to perform the relative magnitude error. In the prototype, the COCOMO set of data is utilized to assess the performance of the regression tools M5 and linear regression. The prototype uses 
the features of COCOMO dataset [19]. The proposal demonstrates that the errors such as MMRE and MdMRE of the M5 algorithm is less as compared to linear regression in forecasting by eighty and forty-five percentages respectively and the anticipation is to reduce the forecasting errors. More investigation is needed to reduce the error forecasting.

Table 1. Limitation of the Existing Literature

\begin{tabular}{|c|c|}
\hline Title & -Limitation \\
\hline $\begin{array}{l}\text { Comparative analysis of software effort estimation techniques } \\
\text { [13] }\end{array}$ & $\begin{array}{l}\text {-It does not deal with the current software project parameters to } \\
\text { compute cost estimations. }\end{array}$ \\
\hline $\begin{array}{l}\text { Generic model of software cost estimation: A hybrid approach } \\
\text { [14] }\end{array}$ & $\begin{array}{l}\text { - The proposed Artificial Neural Network (ANN) based cost } \\
\text { estimation hybrid model needs testing in a real time case study } \\
\text { to conclude the results. }\end{array}$ \\
\hline $\begin{array}{l}\text { A Collective study of PCA and neural network based on } \\
\text { COCOMO for software cost estimation [15] }\end{array}$ & $\begin{array}{l}\text { - The proposed ANN based hybrid model is at the experimental } \\
\text { stage and there is a need to test it using an industrial case study } \\
\text { to infer the results. }\end{array}$ \\
\hline $\begin{array}{l}\text { Enhancement of prediction accuracy in COCOMO model for } \\
\text { software project using neural network [16] }\end{array}$ & $\begin{array}{l}\text { - The validity of the ANN based model needs to be judged with } \\
\text { a case study. }\end{array}$ \\
\hline $\begin{array}{l}\text { Tools \& methods for software effort estimation using use case } \\
\text { points model-A review [17] }\end{array}$ & $\begin{array}{l}\text { - The research concludes that the use case points model is more } \\
\text { reliable as compared to the other cost estimation models } \\
\text { without providing experimental results. }\end{array}$ \\
\hline COCOMO Estimates Using Neural Networks [18] & $\begin{array}{l}\text { - ANN based model (using COCOMO 1) is proposed but it } \\
\text { needs to validate further using COCOMO } 2 \text { and agile projects. }\end{array}$ \\
\hline $\begin{array}{l}\text { Regression Techniques in Software Effort Estimation Using } \\
\text { COCOMO Dataset [19] }\end{array}$ & $\begin{array}{l}\text { - The research lacks to minimise the errors in software cost } \\
\text { estimations. }\end{array}$ \\
\hline Using the Delphi method [20] & $\begin{array}{l}\text { - The data is taken from the simple and qualified experts to } \\
\text { conclude the results and thus a factor of biasness effects the } \\
\text { derived results. }\end{array}$ \\
\hline Software Estimation using a Combination of Techniques [21] & -It does not include size estimation. \\
\hline $\begin{array}{l}\text { Software effort estimation with a generalized robust linear } \\
\text { regression technique [22] }\end{array}$ & $\begin{array}{l}\text { - Linear variate regression technique is used to conclude the } \\
\text { results without comparing with the LQS, MLS and OLS. }\end{array}$ \\
\hline $\begin{array}{l}\text { An Impact of Linear Regression Models for Improving the } \\
\text { Software Quality with Estimated Cost [23] }\end{array}$ & $\begin{array}{l}\text {-It does not cover software cost estimation and how to reduce } \\
\text { the development cost and time. }\end{array}$ \\
\hline Modeling expert effort estimation of software projects [24] & $\begin{array}{l}\text { - The proposed ANN hybrid model uses a small dataset to } \\
\text { conclude the results and there is a need of large dataset to } \\
\text { check the effectiveness of proposed model. }\end{array}$ \\
\hline Analysis of the Techniques for Software Cost Estimation [25] & $\begin{array}{l}\text { - The paper examines only existing estimation models and it } \\
\text { does not offer a novel model. }\end{array}$ \\
\hline
\end{tabular}

Lilja et al. [20] implement Delphi to explore its usability. Delphi technique is used to assemble complex qualitative data from advisors and simple groups of qualified experts. Two variant research studies are introduced using traditional and modified Delphi methods. Lilja et al. [20] discuss the factors to be taken into account when one uses the Delphi method to assemble data. It is concluded that Delphi method is preferred as per the nature of data to be assembled such as health, social and medical disciplines. The proposed software estimation technique is a blend of existing cost estimation techniques [21]. As per the nature of a project, the manager should select a suitable model to do software economics. The software cost estimation challenges are required to be recognized. In order to increase the accuracy of software estimations, a project manager needs knowledge, skills, techniques, and tools in order to meet or exceed the stakeholders needs and expectations from the project [21]. A software cost estimation method is proposed using function point [21]. The proposal 
helps the software industry to compute effort, schedule, and cost that are required to develop the project. The proposed research does not include the size estimation [21].

Linear robust regression method is applied to perform empirical estimations and least median of squares (LMS) are computed [22]. LMS is composed of lessening the sum of the squared residuals. The dataset is collected from the four software development projects to conclude the results. An impact of the linear regression model over the quality of software cost estimation is discussed [23]. It is highlighted that most of the organizations are spending enormous cost to deal with the errors and defects. Both quantitative and qualitative management techniques are applied to control the bugs using historical data. With good planning, the quality of the project will improve continuously and results in the cost-effectiveness. The key purpose of the proposal is to reduce the errors and improve the accuracy of software cost estimation. Karna and Gotovac [24] propose an effort estimation model. The proposed model targets to specific environments where the expert methods are used to develop software products. The proposed model is used to generate the top predictors that are helpful to perform accurate effort estimation. The predictors are used to identify each essential variable input requiring during the prediction process. Despite the efforts that are exerted by the experts, there are numerous unaddressed challenges related to the accuracy of effort estimation. Pandey [25] analyzes the software cost estimation techniques. Majority of cost and effort estimations are employing Fuzzy logic and logarithm models. It is always difficult in software industry to have accurate software cost and effort estimations.

Using the regression technique, an activity model is proposed to estimate human activities such as sitting, standing and walking [26]. The challenges in the quantification of human activities are discussed. Multivariate regression (MVR) technique is used to conclude the results. MVR and multivariate linear regression (MLR) analysis are compared and it is found that MVR is more accurate than the MLR. A tool is proposed to estimate the cost and risk of software projects [27]. The objective of this research is to combine function point and risk management process. The cost of a project is estimated using function point as an input to the proposed tool. The risk estimation is calculated using risk assessment. The proposed solution is simple and seems easy to be used for the software project. A further study is needed to improve the accuracy of the proposed solution. Main limitations of the related work are provided in Table 1.

\section{Research Motivation and Questions}

Changing requirements have a huge impact on the development of a software project and risks will penetrate if proper procedures are not followed to introduce changes in requirements. Changing requirements may lead to failure due to over budgeting and extra scheduling. Therefore, there is a need for a well-organized requirement change management process to tackle only genuine requests from the stakeholders. Sixty-four percent of software projects failed due to lack of management support, unclear and unassigned tasks, and poor change management process [28]. The existing software estimation techniques are not accurate to avoid the risks. Consequently, there is a pressing need to propose a suitable method to solve the problem of the software industry. This study proposes a model that will help project managers in identifying, estimating, mitigating and managing the risk of changing customers' requirements. Following are the research questions taken up in this research.

Q1: How to identify the risks of changing requirements using the proposed model?

Q2: How to mitigate risks associated with changing requirements using the proposed model?

Q3: How to estimate the accuracy of the proposed model as compared to the existing models? 


\section{The Proposed Solution}

The proposed solution is based on three goals to address and mitigate the risks that are associated with changes in requirements. In addition, the proposed model assesses, reduces and manages the risks of changing requirements during the development phase as shown in fig. 1.

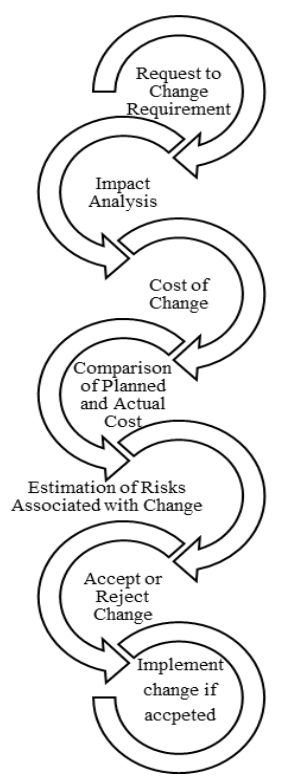

Fig.1. The Proposed Model to Induce Changes in Requirements

This paper addresses the following goals:

Goal 1 - Impact analysis.

Goal 2 - Re-estimate the software project.

Goal 3 - Manage and mitigate the differences.

Impact analysis is used to estimate the risks of changing requirements. A set of metrics is proposed to estimate the impact of changing requirements using statistical analysis. Program evaluation and review technique (PERT) is applied by taking the maximum (pessimistic), minimum (optimistic) and average (realistic) values. Function point analysis (FPA) is used to calculate the size of a software project after requirements are changed. FPA will be used with basic and intermediate Constructive cost model (COCOMO) to calculate time and effort and cost. The next step is to aggregate the classified inputs such as Effort 1, Effort 2, and Effort 3. PERT estimation technique is used for each classified values separately. The project manager will compare the estimated time, effort and cost with initial estimation of a software project to decide the vulnerability and exploitability risks in order to manage and mitigate the differences.

\section{Validation of the Proposed solution}

The proposed model is validated using a case study. The case study is conducted in Saudi Electricity 
Company (SEC) KSA. The case study is to develop a system that will be used to promote the employees of SEC using specific criteria such as working hours and productivity. Table 1 shows that the effort, time and cost estimations using the proposed models are 50 person months, 9 months and $60 \mathrm{~K} \mathrm{SAR}$. The effort, time and cost estimations using the proposed model are significantly better than the existing basic COCOMO, intermediate COCOMO and COCOMO 2 as shown in Table 2.

Table 2. Comparison of the existing and proposed models.

\begin{tabular}{ccccc}
\hline Parameters & $\begin{array}{c}\text { Basic } \\
\text { COCOMO }\end{array}$ & $\begin{array}{c}\text { Intermediate } \\
\text { COCOMO }\end{array}$ & $\begin{array}{c}\text { COCOMO } \\
\text { II }\end{array}$ & $\begin{array}{c}\text { The } \\
\text { proposed } \\
\text { model }\end{array}$ \\
\hline Effort & 36.07 & 55.00 & 52.32 & 50.06 \\
Time & 9.71 & 7.84 & 12.48 & 9.89 \\
Cost & 432840 & 660000 & 627840 & 600720 \\
\hline
\end{tabular}

Table 3. Comparison of the MRE Values of existing and proposed models.

\begin{tabular}{ccccc}
\hline MRE & $\begin{array}{c}\text { Basic } \\
\text { COCOMO }\end{array}$ & $\begin{array}{c}\text { Intermediate } \\
\text { COCOMO }\end{array}$ & $\begin{array}{c}\text { COCOMO } \\
\text { II }\end{array}$ & $\begin{array}{c}\text { The } \\
\text { proposed } \\
\text { model }\end{array}$ \\
\hline Effort & 0.25 & 0.15 & 0.09 & 0.04 \\
Time & 0.46 & 0.56 & 0.31 & 0.45 \\
Cost & 0.25 & 0.15 & 0.09 & 0.04 \\
\hline
\end{tabular}

In order to check the accuracy of the proposed model, we measure the average estimation technique accuracy by using the mean scale of relative error (MRE). Table 3 shows that the proposed estimation model is better than the basic COCOMO, Intermediate COCOMO, and COCOMO II by comparing the MRE values. The results of Tables 2 and 3 clearly show that the proposed cost estimation model is better than the existing cost estimation models.

\section{Conclusion}

A hybrid cost estimation model is proposed in this research. This is accomplished in three steps. First, a set of metrics is proposed to calculate and analyse the impact of risk of changing requirements. Second, the hybrid estimation technique is proposed to estimate the effort, time and cost of the risks associated with the changing requirements. Third, this research proposes a guideline in order to help the project managers to monitor the risks properly. The hybrid proposed estimation model shows improvements in estimations of average error rate and accuracy as compared to the existing cost estimation models. The proposed estimation model is validated using small size software projects to conclude the results. Future work is to apply proposed estimation model on medium and large size software projects to generalize the results. 


\section{References}

[1] Newton P. Managing Project Risk Project Skills. BookBoon.com; 2015.

[2] Balaji N, Shivakumar N, and Ananth VV. Software cost estimation using function point with non algorithmic approach. Glob J Comput Sci Tech 2013;13:1-7.

[3] Chowdhury AAM, and Arefeen S. Software risk management: importance and practices. Int J Computer and Information Technology (IJCIT) 2011;2:49-54.

[4] Mittal S. Risk Analysis and Mitigation Steps in Different Phases of Software Development. Int J Sci Res 2013;2:241-243.

[5] Nolan AJ, Abrahao S, Clements PC, and Pickard A. (2011) Requirements Uncertainty in a Software Product Line. Proc 15th Int Conf Software Product Line, Munich, Germany, 223-231.

[6] Davey B and Parker KR. Requirements elicitation problems: a literature analysis. Issues Informing Sci Inf Tech 2015;12:71-82.

[7] Fu Y, Li M, and Chen F. Impact propagation and risk assessment of requirement changes for software development projects based on design structure matrix. Int J Proj Manag 2012;30:363-373.

[8] Devesh S and Priyank DH. Effective Risk Management Techniques in Development of IVR Software. Int J Comput Sci Tech 2013;4:87-90.

[9] Hijazi H, Alqrainy S, Muaidi H, and Khdour T. Risk factors in software development phases. Eur. Sci. J. ESJ 2014;10:213-231.

[10] Nerkar LR and Yawalkar PM. Software Cost Estimation using Algorithmic Model and Non-Algorithmic Model a Review. Int J Comput App 2014;2:4-7.

[11] Bhatti MW, Hayat F, Ehsan N, Ishaque A, Ahmed S, and Sarwar SZ (2010). An investigation of changing requirements with respect to development phases of a software project. Proc Int Conf Comput Info Sys and Ind Mgmt App (CISIM), Krackow, Poland, 323-327.

[12] Gupta A, Mishra N, and S. Kushwaha DS (2014). Rule based test case reduction technique using decision table. Proc Int Conf Adv Comput, Gurgaon, India, 1398-1405.

[13] Suri PK and Ranjan P. Comparative analysis of software effort estimation techniques. Int J Comput App 2012;48:12-19.

[14] Patil LV, Waghmode RM, Joshi SD, and Khanna V (2014). Generic model of software cost estimation: A hybrid approach. Proc Int Conf Adv Comput, Gurgaon, India, 1379-1384.

[15] Waghmode RM, Patil LV., and Joshi SD. A Collective Study of PCA and Neural Network based on COCOMO for Software Cost Estimation. Int J Comput App 2013;74:25-30.

[16] Madheswaran M and Sivakumar D (2014). Enhancement of prediction accuracy in COCOMO model for software project using neural network. 5th Int Conf Computing, Commun and Networking Techs (ICCCNT), Hefei, China, 1-5.

[17] Saroha M and Sahu S (2015). Tools \& methods for software effort estimation using use case points model-A review. Proc Int Conf Commun Auto Comput, Noida, India, 874-879.

[18] Kaushik A, Chauhan A, Mittal D, and Gupta S. COCOMO Estimates Using Neural Networks. Int J Intell Sys App 2012;4:22-28.

[19] Anandhi V and Chezian RM (2014). Regression Techniques in Software Effort Estimation Using COCOMO Dataset. Proc Int Conf Intell Comput App, Coimbatore, India, 353-357.

[20] Lilja KK, Laakso K, and Palomäki J (2011). Using the Delphi method. Proc Int Conf Technology Management in the Energy Smart World (PICMET), Portland, OR, USA, 1-10.

[21] Nielsen K, Software Estimation using a Combination of Techniques. USA: Proj Manag Inst; 2013.

[22] Lavazza L and Morasca S (2012). Software effort estimation with a generalized robust linear regression technique. Proc 16th Int Conf Eval \& Assessment Software Engineering, Ciudad Real, Spain, 206-215.

[23] Marandi AK and Khan DA. An Impact of Linear Regression Models for Improving the Software Quality 
with Estimated Cost. Procedia Comput Sci 2015;54:335-342.

[24] Karna H and Gotovac S (2015). Modeling expert effort estimation of software projects. Proc 22nd Int Conf Software, Telecommun and Comp Networks, Split, Croatia, 356-360.

[25] Pandey P (2013). Analysis of the Techniques for Software Cost Estimation. Proc 3rd Int Conf Adv Computing and Commun Techs, Rohtak, India,16-19.

[26] Bhuvaneswari PTV, Gayathri S, and Priyadharshini AS (2014). Activity Estimation Using Regression Technique. Proc Int Conf Comput Intelli and Commun Networks, Bhopal, India, 1177-1183.

[27] Kaushik A., Soni AK, and Soni R (2012). An adaptive learning approach to software cost estimation. Proc Int Conf Comput and Commun Syss (NCCCS), Durgapur, India, 1-6.

[28] Kumar SA and Kumar TA. Study the impact of Requirements management Characteristics in global software development projects: An Ontology based approach. Int J Softw Eng Appl 2011;2:107-125.

\section{Authors' Profiles}

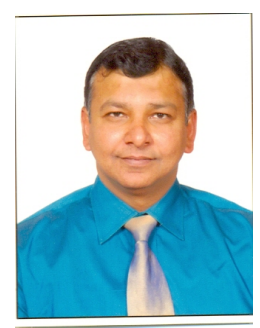

Dr. M. Rizwan Jameel Qureshi received his Ph.D. degree in Computer Sciences from National College of Business Administration \& Economics, Pakistan 2009. He is currently working as a Professor in the Department of IT, King Abdulaziz University, Jeddah, Saudi Arabia. This author is the best researcher awardees from the Department of Information Technology, King Abdulaziz University in 2013 and 2016. He is also honoured as the best researcher from the Department of Computer Science, COMSATS Institute of Information Technology, Pakistan in 2008.

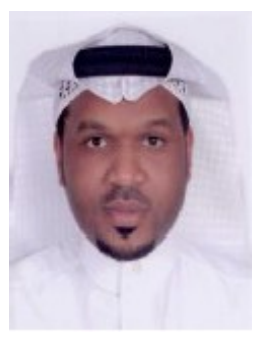

Mohammad D. AlJohani received his M.Sc. IT degree from the Dept. of IT. King Abdulaziz University SA, 2018.

How to cite this paper: Mohammad D. AlJohani, Rizwan Qureshi. " Proposed Risk Management Model to Handle Changing Requirements", International Journal of Education and Management Engineering(IJEME), Vol.9, No.5, pp.18-25, 2019.DOI: 10.5815/ijeme.2019.05.03 